\title{
User Interface Cultures of Mobile Knowledge Workers
}

\author{
P. Mannonen \\ Helsinki University of Technology, Finland
}

\begin{abstract}
Information and communication tools (ICTs) have become a major influencer of how modern work is carried out. Methods of user-centered design do not however take into account the full complexity of technology and the user interface context the users live in. User interface culture analysis aims providing to designers new ways and strategies to better take into account the current user interface environment when designing new products. This paper describes the reasons behind user interface culture analysis and shows examples of its usage when studying mobile and distributed knowledge workers.
\end{abstract}

Index Terms-mobile work, user-centered design, user interface cultures.

\section{INTRODUCTION}

User-centered design is based on the design decisions in understanding the target users. Information about the users and their surroundings are gathered in various ways and from multiple viewpoints. The aim is to produce a holistic understanding that can be utilized both in designing a product and evaluating the designs $[1,9,11]$.

Since user-centered design emphasizes the versatile understanding of users, it is quite natural that multiple methods for doing user research and analyzing user research results have been developed to take into account different situations and users to which and whom the products are developed. Though the user research methods and analysis frameworks are manifold they do not cover all possible situations the designers may and do confront [6].

For example Contextual Design defines five different work models that are developed for analyzing workflows and practices. Models take into account the communication and coordination necessary to do the work, detailed work steps necessary to achieve goals of work, physical things created to support the work, constraints of the work, and physical structure of the work [1].

Gaver, Dunne and Pacenti [4] took a somewhat different stand in their Cultural Probes method. Cultural probes were developed to provoke inspirational responses from the users (originally elderly people). Other wellknown user research methods and toolboxes include usability evaluations, task analysis, focus groups, and expert reviews [19].

In addition to changing design subjects and target user groups also urgency in product development puts pressure to method development. Basic methods of user research, namely observations, interviews and questionnaires, come from other fields of science and require extensive amounts of time to be conducted properly. Thus new methods, such as rapid ethnography, for hastening the research have been developed [13].

While studying users in more and more complex settings and tasks designers have seem to forgot a more general level change in the world. The world we live in has become more and more altered and designed by us and other people living in it. As Hughes [7] puts it we live in a "Human-Built World". This phenomena is perhaps most visible when information and communication technologies (ISTs) are considered. Both the communication we have with our friends and family and the information we need to establish the communication is based on growing number of technologies and technical systems. It seems that almost everything we do involve some kinds of relations to technologies [12].

Distributed and mobile workers are a extremely good case for studying the role of technology in users' work and context of work, since the use and sometimes even reliance of ICTs is one of the main characteristics of distributed and mobile workers [2, 3, 17].

This article represents an analysis point of view for understanding the technological context the users act in. The analysis is applied in a case of distributed and mobile knowledge workers.

\section{USER INTERFACE CULTURES}

The traditional ways the user-centered design practices take into account current technologies and user interfaces the users use resemblances to competitor analysis. The underlying assumption in analyses is that new "more usable" solutions probably will make at least some old tools obsolete by providing better ways to do the tasks or by changing the tasks themselves. These kinds of analyses are usually called artifact analyses [1,5].

Bayer and Holtzblatt [1] focus in their artifact analysis on physical objects, e.g. paper calendars, shopping lists and printed documents. As part of inquiry the use and creation of artifacts is observed. In analysis phase an artifact model that represents how real-world objects are used and why they are important is created.

Hackos and Redish [5] define their artifact analysis as a "functional description of the artifacts (objects) collected from the users and that are used in the performance of tasks with implications and ideas for design of new or improved products and processes” (pp. 301). The aim is to understand enough about the task artifacts to be able to translate the meaning and functionality of them into the new product environment. In this sort of analysis artifacts are used to gather information about how the users approach their work. 
The above mentioned traditional artifact analyses seem to fail to notice technical artifacts and the deep relationships between users and artifacts (tools and devices). Important unanswered questions that remain are, for example, 'How the users see, understand and experience certain tools and devices?' and 'How the artifact and user interface environment affect how the users see, understand and experience new devices and their user interfaces?'.

Modern technology and especially ICTs are in essence enabling technologies [15]. This means that the actual meaning of the ICT tools and devices is vague. Tools and technologies enable activities but the actual use and users select what they do with the devices and thus define the functionality of the devices from their perspective.

Since a person's knowledge and know-how affects on how he or she perceives new things and events, target user group of developed system or device can have multiple and even contradictory perspectives on technology and user interfaces. Culture is traditionally defined as a shared understanding and knowledge between groups of people [8]. If user interface culture is defined the same way as a shared understanding and knowledge about technologies and their user interfaces, members of a user group for certain devices can belong to different user interface cultures.

In user-centered design culture is usually seen as national or regional phenomenon. Interest in cultural aspects has grown during recent years but still culture is understood as very large-scale concept [10].

User interface culture analysis aims at producing information and tools for designers to help them design solutions that take into account, fit into, and cultivate user interface cultures of the users. User interface cultures are analyzed in user-centered way. The focus is on single or small groups of users and not in large populations or nations. User interface culture analysis produces information about how the users approach technology and user interfaces, what is their competence on using them and what is their know-how of technical or interaction possibilities.

\section{CASE Study: Distributed AND MOBILE KNOWLEDGE WORKERS}

The research was a part of dWork - Distributed Workplace research project conducted during years 20042006. The project focused on studying the kinds of challenges faced in designing and managing the workplaces of the new type of distributed and mobile workers [18].

The case in which user interface culture analysis was applied considered a team of eight mobile and distributed workers. Team members did not have own permanent workplaces at the office and used shared office premises instead. Meetings filled major part of the team members' office time and thus they worked a lot in meeting rooms also. The team's goal was to develop organizational mobility of the company. Each team member had his or hers own area of responsibility and expertise and the team had problems in effective collaboration. Team members communicated together mainly via electronic means and meat each other face-to-face only seldom.

\section{A. Research Methods}

The team was studied in two phases. In the first phase a critical incident method was used where it is a derivative of the cultural probes method [4]. In used variation, participants took pictures of specific parts of their daily lives and afterwards interview sessions that focused on photographed events were organized [12]. The first phase focused on studying the kinds of technologies and tools the workers used and in what kinds of situation and environment they worked in. Thus the participants were given a task to photograph spaces, activities and tools that were related to their work [14].

The second phase was based on the first phase's findings that different meetings formed a major part of the participants' workdays. Meetings are so central to the studies of distributed and mobile workers' work that most of them organized their whole workdays in nested meetings. Sometimes they even booked meetings just for themselves to do tasks that required concentration or to make sure that they had time, for example, to prepare for upcoming meetings. During the second phase of the research, the different communication episodes (e.g. meetings) which the workers participated in were observed and people participating in the episodes interviewed. The observed communication episodes were selected in co-operation with the studied workers.

\section{B. Results}

The team members' basic set of tools were very homogenous. The company policy offered more or less the same devices for every worker irregardless of the actual work. All team members had a laptop computer, mobile phone, hands-free kit for the phone, encryption card, and a bunch of battery chargers for computer, phone and e.g. Bluetooth hands-free kit.

One team member decided to have as little tools with him as possible and had just a post-it note stuck on his computer and a pen with him in addition to the basic toolset. Other team members carried briefcases, printed documents, notebooks, etc. with them.

In addition to the carried tools, the available software was basically the same amongst team members. All the software was available to the team members and company policy restricted tailoring of user interfaces. Thus the team members' computers looked and behaved almost identically. However, even the quite simple device and software collection resulted to situations where the workers could select from many different combinations of devices and software to accomplish their task.

Although the toolsets of the team members and also all other company's workers' were somewhat identical, the collaboration events proved to be extremely complex in context wise. The collaboration context had five main dimensions: physical environment, technological environment, tasks and goals, practices and methods, and products or concrete results of the collaboration (fig. 1). Each dimension is connected to every other dimension. For example, certain environment supports or obstructs the usage of certain tools (e.g. one cannot use laptop computer while driving a car but can talk to phone via hands free) and supports or obstructs certain practices for example, "wild and noisy" brainstorming techniques can be used in meeting rooms but not in open office spaces [18]. 


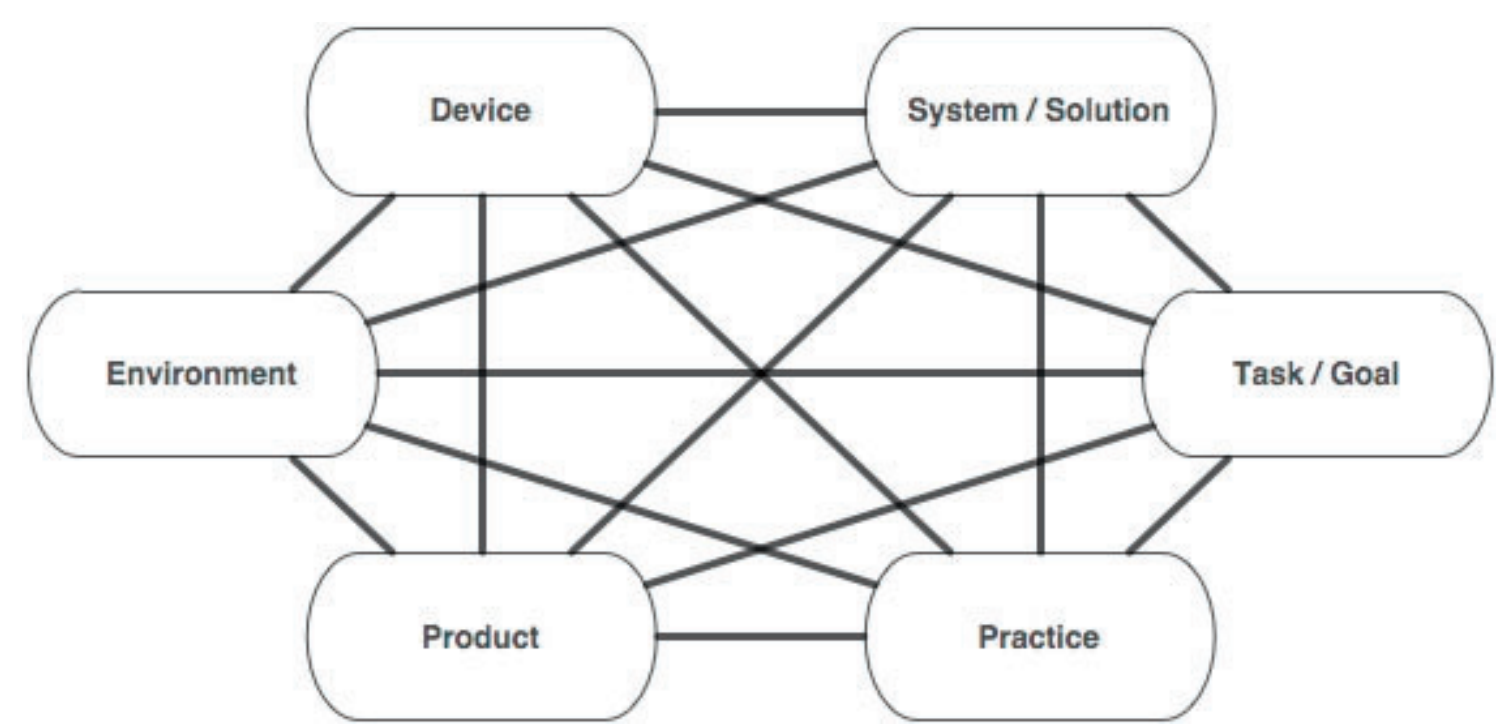

Figure 1. The collaboration context of distributed and mobile workers. All the dimensions of the context, device, system/solution, task/goal, practice, product, environment, are connected to each other dimension. (Vartiainen, et al. 2007).

Each participant saw these dimensions from his or her own perspective and had difficulties in understanding other participants' point of views. Dimensions are closely linked. The most interesting one, when user interface cultures are considered, is technological environment.

Technological environment consist of both devices and systems that are used with the devices. In some cases the link between device and a system is strong, e.g. between mobile phone and text message or between computer and Internet Relay Chat (IRC). The situation is, however, changing quickly. For example, SMS's can be sent via PC's and new smart phones can handle IRC and other web services that are traditionally linked to PC's. All in all, technological devices and systems form an extremely complex network of possibilities and the workers need to select most suitable combination for each task. The selecting is made based on personal working habits, knowledge of technology, and competence on using the devices and systems, i.e. user interfaces.

Problems occurred when the participating workers preferred different technology-system combinations or had different levels of competence on using the selected devices or systems. Respectively the successes happened when all the participants thought that the selected technology or system was most suitable for a task in hand.

However, collaborative selecting of the technologies for meeting or collaboration event was not a regular task. Usually the meeting organizer selected the medium for collaboration.

\section{Analysis}

From the company's IT supports perspective the provided devices and systems enable distributed and mobile communication between people and using of remote resources from almost any imaginable location. As a matter a fact the workers can even choose between different ways of communicating with their coworkers and utilizing remote resources. Since the IT support personnel are IT professionals their views of the selected and provided technologies are usually hard to challenge. However, their viewpoint is just one of many possible ones and should not be seen as the only viewpoint. In many situations the viewpoints of the workers who actually have to use the selected devices and software should be more important and have more influence compared to the technology professionals' viewpoints.

The studied team members encountered problems almost daily when trying to accomplish their tasks. The majority of problems were related on collaboration between people and in situations where some of the participants were not familiar with the used collaboration tool or the tool just did not have all the needed functionalities. In some cases the workers had contradicting knowledge and opinions about the tools being used or solutions that it seemed as if they were using completely different tools. The most successful communication events were noted by those participants who had similar knowledge, opinions and experiences about the used tools. Comparing this to phenomena to the Inglis's definition of cultures i.e. shared understanding and knowledge, the workers can be seen to represent members of several different user interface cultures.

Habits of selecting the items (technologies and user interfaces) that the mobile worker carries with him or her divide the studied mobile workers in two categories: a) pure digital, and b) paper carriers. All the workers said that they tried to minimize paper usage since paper is heavy to carry around. However the paper carriers still printed some important documents and for example used notebooks for note taking while the pure digitals had learned to make all notes and memos, and also commenting on other people's writing using digital tools. The noticeable level of user interface cultures in this division is quite general, and the problem and possible solutions to it can be noted apart from applying user interface culture analysis. The traditional way has been to for example see that digitalization has brought changes and people need to learn new ways of working with new digital tools. However, the user interface culture approach may suggest a different solution. If the situation is considered as two different cultures colliding and not as a working habit (printing documents), that may be resolved 
by new technical solution, whilst the design solutions are more multidimensional. Changing a culture of, for example, printing documents for reading and handling is extremely difficult. Instead the designers should look into how different cultures can coexist and collaborate. In addition to for example creating annotation tools in document handling software (supporting the pure digitals' culture) also printing and scanning (digitalizing the hand made notes and thus supporting the paper carriers culture) features should be developed. This way, the user interface culture design viewpoint opens up interesting possibilities that can even reduce resistance by many of those who are adopting new technologies.

Since the communication and collaboration between people is the most common problem, next step is to dwell deeper into the user interface culture relating to them. The most used tools for remote and thus technology-based communication is email, chat and instant messaging. The team members saw the utility and possibilities of email quite differently from one another. Some used email as main information resource and repository. They sent documents and long email messages regularly. They also expected the recipients to use email as intensively and systematically as they did, and will be amazed if someone did not behave so or, for example, did not respond to their emails in a few hours or at least within one day or did not read the full email conversation thoroughly before commenting or participating. Other main group considered email as a news feed that should be monitored when possible but that there is only rarely need to check old messages, i.e. messages that are not anymore part of 10 or 20 newest emails. The same group also read the emails fleetingly and sometimes dismisses long emails.

The email using style was linked to chat and instant message using style of the workers. Those basing their communication and information on emails considered instant messaging as a status information medium and chat as informal information channel. The ones considering email as some sort of news feed used instant messaging for asking quick questions and inviting people to ad-hoc (chat) meetings. For them, chat is perhaps the most important tool after word processors. They participated and organized regularly distributed meetings via chat. Those considering chat conversations as informal communication preferred teleconferencing for remote meetings.

Problems relating to different competencies of using certain tools or systems were most visible in the chat usage. Heavy chat users frequently utilize document sharing and other advanced features, and also appeared to participate in just some parts of the meeting which interest them. Some of the more infrequent users of chat had not even noticed the possibility of, for example, sharing document in chat sessions and participated in chat meetings like in traditional meetings in meeting rooms, i.e. they preferred to be present few minutes before the meeting started and participated in the whole meeting. They were also a bit more concerned about the messages they sent and sometimes even wrote the message in word processor software and copy pasted it them to the chat conversation window.

The different cultures in using communication and collaboration tools (email, instant messaging and chat) yield new kind of designs for such tools. The tools should let the users select the mediums they wish to use for receiving and sending information more freely and also enable cross-medium collaboration. Examples of these kinds of solutions could be sending email messages to a chat meeting, subscribing chat conversations as emails or RSS-feeds, and sending documents that have been shared or created in chat meetings to some participants as email attachments.

Customizing user interfaces of newer tools to resemble other more familiar user interfaces, i.e. to obey user interface culture norms of the user, is another new design guideline. This is a bit similar to the old rule of speaking in the user's language but adopting this to the user interfaces which the user uses.

\section{CONCLUSIONS}

Orr [16] noticed that knowledge work is invisible by nature, meaning it is impossible to understand work by just observing it. As mentioned earlier, technologies have been included in almost every aspect of life. At the same time the technical devices have become more and more opaque. And nowadays it is difficult to understand the true meaning and usage of the device or system by just seeing what the system can do or what kind of technology the system includes. It seems that the ICT tools and devices have become so integrated to knowledge work that they too are sometimes invisible to practitioners of usercentered design.

The reported case study shows that workers equipped with similar communication tools and devices can have a very different understanding and opinion about the tools that although they can use the tools they have difficulties when trying to collaborate with one another. The different opinions and conceptions are based on users knowledge and both personal and shared experiences with different technologies. Also both self-learned (informal) and outside-instructed (formal) ways of using technologies mould the understanding and viewpoints.

This situation is near the traditional definitions of culture, i.e. shared understanding and knowledge between groups of people [8]. Since the understanding and knowledge is concerned with technologies and user interfaces, we can speak about user interface cultures. Looking at the technical context of the users from a user interface culture's point of view can give designers new ideas and strategies for better supporting both individual and groups of users with their tasks.

The need for new designs is especially obvious in distributed and mobile work. The ICT technologies and systems evolve rapidly, and distributed and mobile workers do not have same possibilities to share their point of views and experiences towards technology and user interfaces as compared to traditional office workers who can and do talk about the new tools informally during coffee breaks, etc. The distributed and mobile workers are in many ways alone out there and, thus, the tools they need to use should adapt to their needs and know-how, and support the evolving user interface culture which they are a part of.

\section{REFERENCES}

[1] Beyer, H. and Holtzblatt, K.: 1998, Contextual Design: Defining Customer-Centered Systems, Morgan Kaufmann Publishers, San Francisco. 


\section{User InTERFACE Cultures of MoBiLe KNOWLEDGE WorKers}

[2] Cramton, C.D.: 2002, Attribution in Distributed Work Groups. In Hinds, K.J. \& Kiesler, S (eds.), Distributed Work, The MIT Press, Cambridge, MA, 191-212.

[3] Evaristo,J. R., Scudder, R., Desouza, K. and Sato, O.: 2004, A Dimensionals Analysis of Geographically Distributed Project Teams: A Case Study, Journal of Engineering and Technology Management, 21(3), 175-189. doi:10.1016/j.jengtecman.200 3.05.001

[4] Gaver, B., Dunne, T. and Pacenti, E.: 1999, Design: Cultural Probes, Interactions, 6(1), 21-29, doi:10.1145/291224.291235

[5] Hackos, J., T. and Redish, J., C.: 1998, User and Task Analysis for Interface Design, Wiley Computer Publishing, New York.

[6] Hagen, P., Robertson, T., Kan, M. and Sadler, K.: 2005, Emerging Research Methods for Understanding Mobile Technology Use, Proceedings of OZCHI 2005, ACM Press.

[7] Hughes, T., P.: 2005, Human-Built World: How to Think about Technology and Culture., University of Chicago Press, London.

[8] Inglis, F.:2004, Culture, Polity Press Ltd, Cambridge.

[9] International Organization for Standardization: 1999, ISO 13407 International Standard: Human-centred design processes for interactive systems, International Organization for Standardization, Geneve.

[10] Kamppuri, M., Bednarik, R. and Tukiainen, M.: 2006, The expanding focus of $\mathrm{HCI}$ : case culture. Proceedings of the NordiCHI 2006, ACM Press, 405-408.

[11] Kuniavsky, M.: 2003, Observing the User Experience: A Practitioners Guide to User Research, Morgan Kaufmann Publishers, London.

[12] MacKenzie, D., and Wajcman, J. (eds.): 1999, Introductory Essay in The Social Shaping of Technology: Second Edition. Open University Press, Buckingham.
[13] Millen, D. R.: 2000, Rapid ethnography: time deepening strategies for HCI field research. Proceedings of DIS 20000. ACM Press, 280-286.

[14] Nieminen, M., P. and Mannonen, P.: 2005, Capturing Mobile and Distributed Work for Concept Development Using Photograph Probes, Proceedings of IASTED-HCI 2005, ACTA Press, Anaheim, USA, 191-196.

[15] Nordic Council of Ministers: 2005, Nordic Information Society Statistics 2005, Statistics Denmark, Copenhagen.

[16] Orr, J.: 1996, Talking About Machines: An Ethnography of a Modern Job, Cornell University Press, London.

[17] Sarker, S. and Sahay, S.: 2003, Understanding Virtual Team Development: An Interpretive Study, Journal of the Association for Information Systems, 4(1), 1-38.

[18] Vartiainen, M., Hakonen, M., Koivisto, S., Mannonen, P., Nieminen, M., P., Ruohomäki, V. and Vartola, A.: 2007, Distributed and Mobile Work: Places, People and Technology, Otatieto, Finland.

[19] Vredenburg, K., Mao, J., Smith, P., W. and Carey, T.: 2002, A Survey of User-Centered Design Practice, Proceedings of CHI 2002, ACM Press, 471-478.

\section{AUTHOR}

P. Mannonen (petri.mannonen@soberit.tkk.fi) is with the Software Business and Engineering Institute of Helsinki University of Technology. P.O. Box 9210, FI02015 TKK, Finland.

This work was supported in part by the GEBSI graduate school.

This article was modified from a presentation at the 21st Symposium on Human Factors in Telecommunication (HFT 2008) in Kuala Lumpur, Malaysia, March 2008. Manuscript received 23 July 2008. Published as submitted by the author. 